\title{
State-of-the-art Nanofabrication in Catalysis
}

\author{
Waiz Karim,,$^{\star a b c}$, Simon A. Tschupp ${ }^{\text {bd }}$, Juan Herranz ${ }^{\mathrm{d}}$, Thomas J. Schmidt ${ }^{\mathrm{de}}$, Yasin Ekincib ${ }^{\mathrm{b}}$, and \\ Jeroen A. van Bokhoven ${ }^{\text {ac }}$
}

§SCS-Metrohm Award for best oral presentation in Catalysis Science \& Engineering

\begin{abstract}
We present recent developments in top-down nanofabrication that have found application in catalysis research. To unravel the complexity of catalytic systems, the design and use of models with control of size, morphology, shape and inter-particle distances is a necessity. The study of well-defined and ordered nanoparticles on a support contributes to the understanding of complex phenomena that govern reactions in heterogeneous and electro-catalysis. We review the strengths and limitations of different nanolithography methods such as electron beam lithography (EBL), photolithography, extreme ultraviolet (EUV) lithography and colloidal lithography for the creation of such highly tunable catalytic model systems and their applications in catalysis. Innovative strategies have enabled particle sizes reaching dimensions below $10 \mathrm{~nm}$. It is now possible to create pairs of particles with distance controlled with an extremely high precision in the order of one nanometer. We discuss our approach to study these model systems at the single-particle level using X-ray absorption spectroscopy and show new ways to fabricate arrays of single nanoparticles or nanoparticles in pairs over a large area using EBL and EUV-achromatic Talbot lithography. These advancements have provided new insights into the active sites in metal catalysts and enhanced the understanding of the role of inter-particle interactions and catalyst supports, such as in the phenomenon of hydrogen spillover. We present a perspective on future directions for employing top-down nanofabrication in heterogeneous and electrocatalysis. The rapid development in nanofabrication and characterization methods will continue to have an impact on understanding of complex catalytic processes.
\end{abstract}

Keywords: Electrocatalysis · Heterogeneous catalysis · Lithography · Nanoparticles · Surface science

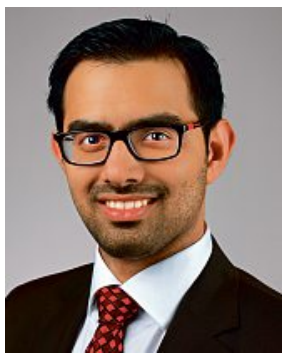

Waiz Karim obtained his PhD (20132017) from ETH Zurich while also working at Paul Scherrer Institute and Swiss Light Source synchrotron (Switzerland). His recent research on nanofabrication and heterogeneous catalysis was published in reputed journals such as Nature, Nanoscale and Scientific Reports. As an

${ }^{*}$ Correspondence: Dr. W. Karim ${ }^{\mathrm{abc}}$ E-mail: waiz.karim@alumni.ethz.ch alnstitute for Chemical and Bioengineering ETH Zurich, $\mathrm{CH}-8093$ Zurich

baboratory for Micro and Nanotechnology Paul Scherrer Institute, $\mathrm{CH}-5232$ Villigen

cLaboratory for Catalysis and Sustainable Chemistry

Paul Scherrer Institute, $\mathrm{CH}-5232$ Villigen

dElectrochemistry Laboratory

Paul Scherrer Institute, $\mathrm{CH}-5232$ Villigen

eLaboratory of Physical Chemistry

ETH Zurich, $\mathrm{CH}-8093$ Zurich
'Erasmus Mundus' scholarship awardee, he earlier completed MSc in Optics and Photonics (2010-2012) from Karlsruhe Institute of Technology (Germany) with a thesis on organic solar cells and also attended Institut Fresnel (France) and UPC-ICFO (Spain). Prior to this, he studied engineering (B.Tech.) at Jamia Millia Islamia, India (2006-2010).

\section{Introduction}

Nanofabrication or nanolithography techniques, that are usually classified as either 'top-down' or 'bottom-up' approaches, have been used to make ordered and functional structures of dimensions below $100 \mathrm{~nm} .^{[1]}$ In fields such as electronics, semiconductors, optics, biological systems, sensors, material sciences, and energy systems, nanofabrication has enabled the creation of new devices, thanks to the increased control of feature size, morphology, topology, and functionality. It has also expanded the applications of already existing devices and materials through miniaturization and has helped to answer fundamental scientific questions. Our recent work, involving the use of topdown methods such as electron beam lithography (EBL) $)^{[2]}$ and extreme ultraviolet
(EUV) lithography ${ }^{[3]}$ has shown that modern nanolithography continue to have great potential in chemical science, specifically in catalysis and related surface chemistry, as feature sizes or/and resolution down to a few nanometers are becoming a reality. Catalysis is ubiquitous in today's society, both for life and lifestyle ${ }^{[4]}$ and between 80 and $90 \%$ of the total chemical products include catalysts at some stage during their production, generating more than $35 \%$ of the gross world product. ${ }^{[5]}$ Common applications are in catalytic converters, used in automobiles for the cleaning of exhaust gases, ${ }^{[6]}$ and in many energy conversion processes employed in the industry. ${ }^{[7]}$ In addition, novel processes and catalysts are required to move away from the use of fossil resources. ${ }^{[8]}$ Significant efforts are therefore undertaken in finding new materials to improve catalysts' performance and develop more sustainable processes. Metal nanoparticles dispersed on high-surfacearea supports are commonly used. These technologically important catalytic systems are very difficult to study and therefore remain not well understood as they are poorly defined in terms of size, shape, and composition. ${ }^{[9]}$ Understanding the structure-activity relation is essential to design novel catalysts or to improve existing ones. This requires effective strategies to obtain 
and characterize these nanoparticles under different conditions, particularly in the form of well-defined model catalysts that allow reducing the parameter space assessed by the study, therefore limiting overlap between different effects while still representing the complexity of a real catalytic system. Achieving the narrow nanoparticle size distribution and precise control of inter-particle distances is needed for model catalyst studies. This is possible by using top-down lithography approaches. Of these, conventional optical lithography or laser interference lithography techniques are resolution-limited and do not allow patterning of sizes below $20 \mathrm{~nm}$. The widely used EBL offers small sizes albeit with constraints in the packing density and with a much lower throughput, thereby limiting the area that can be covered by the particles. These can be overcome either by using next-generation top-down methods such as EUV lithography at $13.5 \mathrm{~nm}$ wavelength allowing for large-area patterning within a fraction of the time required by EBL, or by employing novel surface science techniques to overcome the poor signal-to-noise ratio. This review aims to give a short overview of the past and present nanofabrication methods to prepare ordered model catalysts and their application in catalysis science, focusing on heterogeneous catalysis and electrocatalysis.

\section{Applications of Top-Down Methods in Heterogeneous Catalysis}

Heterogeneous catalysis involves chemical reactions accelerated with the aid of a solid surface, often in the form of small particles of transition metals, such as gold, platinum, iron, silver, and palladium. The smaller these are, the larger is their surface-area-to-volume ratio, and tuning their size controls their reactivity. ${ }_{[2}^{[2,10]}$ Decreasing the particle size makes them less stable and they must be stabilized, which is done by using a support of a large surface area. The supports are often metal oxides, such as alumina, silica, titania, and carbon, onto which the catalyst particles are anchored, ideally well spread out to prevent contact with each other. In many cases, the support takes an active role in the reaction mechanism and they cannot be seen as chemically inert. Model catalysts are used to simplify the interplay between the physical/chemical properties of the catalyst particles and the support, so as to gain insight into the structure-activity relationship which, in turn, helps to design improved 'real' catalysts. For example, one such challenge is to identify the structure of the active phase at the surface and to understand the dependence of adsorp- tion interactions and catalytic reactivity on particle size. The evolution in surface science methods has been directly linked to the possibility of designing and characterizing new model systems - single crystal surfaces of metals were studied initially, followed by metal oxides in the form of thin films and leading the way to probe metal-on-metal oxide. [11] Ordered arrays of well-defined metal nanoparticles on a support, which can best be prepared using top-down nanofabrication, is a sought-after model system that would allow precise understanding of the effect of particle spacing and size on adsorption and reaction. The metal-support interaction and the inter-particle region takes an even more important role in a number of processes, such as the spillover effect.[12] Hydrogen spillover, i.e. the surface migration of hydrogen atoms from a metal catalyst where they are generated onto and away from the catalysts support, has been a widely debated subject ${ }^{[13]}$ where the nature of the support and the distance from the metal catalyst plays a crucial role (details in section 4.2).[2a] The main requirements for the nanofabrication strategies used to create these ordered arrays of nanoparticles are: (a) to obtain catalytically active particles of sizes below $20 \mathrm{~nm}$, (b) to have small inter-particle distances (pitch) and a correspondingly high packing density, and (c) to obtain these particles uniformly over a large area enabling to achieve good signal-to-noise ratio when characterizing these surfaces with, for example, X-ray photoelectron spectroscopy (XPS), X-ray diffraction (XRD), transmission electron microscopy (TEM) and X-ray absorption spectroscopy (XAS). ${ }^{[14]}$

\subsection{Ordered Nanoparticle Arrays using $E B L$}

EBL is a very effective method to achieve nanoparticle arrays in the size range below $20 \mathrm{~nm}$, which is most relevant in heterogeneous catalysis (see recent examples in Figs. 1-3). Somorjai and co-workers ${ }^{[15]}$ used EBL-prepared platinum nanoparticles of $50 \mathrm{~nm}$ diameter (15 $\mathrm{nm}$ height) with $200 \mathrm{~nm}$ pitch on a silicon wafer to perform ethylene hydrogenation and showed high stability of these systems under UHV conditions. These were investigated by XPS, Auger electron spectroscopy (AES), scanning electron microscopy (SEM), atomic force microscopy (AFM) and temperature programmed desorption (TPD). In a similar manner, they later studied ${ }^{[16]}$ the thermal stability of EBL-prepared silver nanoparticles of 25-30 nm in diameter and $10-15 \mathrm{~nm}$ in height, which were deposited on alumina (coated on silica) with a pitch of $100 \mathrm{~nm}$. These square nanoarrays of periodically spaced cylinder-shaped particles, so-called high-technology model catalyst, were investigated by high-resolution TEM, in addition to the previously mentioned techniques. Their subsequent studies of carbon monoxide adsorption using sum frequency generation vibrational spectroscopy ${ }^{[17]}$ in test reactions showed that these particles are catalytically active for hydrocarbon conversion. ${ }^{[18]}$ Kasemo and coworkers ${ }^{[19]}$ also used EBL to fabricate platinum nanoparticles down to $30 \mathrm{~nm}$ in diameter on supports such as alumina and ceria and they designed a microreactor to enhance the samples' catalytic sensitivity, needed because of their small coverage and low surface area. In a separate study, ${ }^{\text {20] }}$ they used selected area electron diffraction (SAED) and TEM to characterize copper arrays of $40 \mathrm{~nm}$ in diameter with different pitch sizes down to $100 \mathrm{~nm}$, which were deposited on a $\mathrm{Si}_{3} \mathrm{~N}_{4}$ membrane coated with a 7-nm-thick film of silica. In the quest to identify active sites in heterogeneous catalysis, EBL-prepared copper particles of 12,35 , and $63 \mathrm{~nm}$ in diameter, around $5 \mathrm{~nm}$ in height and with a pitch of 100-150 nm were supported on silica by Burghaus and colleagues, ${ }^{[21]}$ who showed evidence of preferential adsorption of carbon monoxide and carbon dioxide along the rim of these particles using techniques such as AES, XPS, and molecular beam scattering. Other studies have obtained particle sizes and pitch of either the same or much larger dimensions, and have employed similar characterization techniques to study butane adsorption on molybdenum particles supported on silica, ${ }^{[22]}$ the thermal, chemical, and mechanical stability of platinum nanoparticles supported on silica, alumina and ceria, ${ }^{[23]}$ and high turnover reactions such as ethylene hydrogenation on platinum nanoparticle arrays. [24] The above-mentioned studies showed the feasibility to generate, characterize and do catalysis over systems generated by topdown nanofabrication; however the sizes of the active components were relatively large.

Model systems prepared by EBL are often not practical for low turnover reactions that require that these nanoparticles are spread over a large area $\left(\sim 1 \mathrm{~cm}^{2}\right)$ and with a pitch as small as possible for practical detection of reaction products. With the pitch around $100 \mathrm{~nm}$, the area over which the nanoparticle arrays are patterned in most of these EBL studies is about a few square millimeters. Because of the sequential nature of EBL, it has very low throughput, limiting the total area of the patterned surface. While it is possible to produce nanoparticles over a larger area, the electron beam exposure of an area of a few square millimeters in size can take hours for a moderate pitch, and increases dramatically (up to a few days) if the pitch is reduced or the exposure area is in- 
creased. In addition, such large-area EBL patterning also results in lower uniformity due to its limited 'writing field' - the largest area exposed without moving the stage. As the pitch is reduced further below $100 \mathrm{~nm}$, new challenges arise in the liftoff process - an important and frequently used final step of nanofabrication involving removal of the photoresist after deposition of metal. Moreover, lithographically prepared ordered nanoparticle arrays with sizes below $10 \mathrm{~nm}$ have not been studied for catalytic reactions because these sizes are not easy to obtain and a pitch of around $100 \mathrm{~nm}$ would lead to insufficient density of particles to provide any useful signal for such small sizes. These small sizes are of high interest in catalysis, exhibiting a different behavior from the larger particles, as there is huge increase in the percentage of surface atoms in the nanoparticles and quantum-size-related properties ${ }^{[25]}$ come into effect for various processes, for examples in catalyst sintering, ${ }^{[10 b]} \mathrm{di}$ rect propylene epoxidation using silver nanoparticle, ${ }^{[10 \mathrm{~d}]}$ water-gas shift (WGS) catalysis over gold,[10c] hydrogen oxidation reaction using platinum ${ }^{[26]}$ and many others. ${ }^{[10 a]}$ Arrays of uniform, well-ordered and shape-defined nanoparticles of the single-digit nanometer size spread over few square centimeters with a pitch of few tens of nanometers for increased density would be an ideal model system.

\subsection{Sub-10 nm-size Particles and Controlled Shape}

Alternative ways to perform EBL over small areas have been applied by Komanicky et al. ${ }^{[27]}$ to study the shape-dependent activity of platinum array catalyst for the electroreduction of oxygen (details in section 3.2). They obtained near perfectly shaped (100), (110), and (111) platinum particle arrays with a pitch of $200 \mathrm{~nm}$ and a height of $7.5 \mathrm{~nm}$ by etching a thin platinum film on a strontium titanate substrate using EBL-prepared hard masks followed by ion milling of the platinum film. This approach can be extended for applications in heterogeneous catalysis when combined with lithography techniques that allow large-area patterning. We recently obtained iron/iron oxide nanoparticles of sizes down to $6 \mathrm{~nm}$ with a thickness of $2 \mathrm{~nm}$ using EBL. ${ }^{2 \mathrm{~b}]}$ Here, each nanosized hole (or nano-well) was patterned by implementing proximity effect correction strategies during EBL exposure, which was followed by optimization of the conditions for resist development, metal deposition and the lift-off process (details on application in section 4.1). This generic strategy can be used to prepare arrays of practically any metal that can be deposited using tools such as thermal evaporation and physical vapor deposition, among others. There are other ways to further reduce particle size below these dimensions, such as the use of tilted evaporation. Inside the nano-wells of a comparatively large diameter of $20 \mathrm{~nm}$ and pitch of $75 \mathrm{~nm}$ prepared by EBL, Javey and Dai ${ }^{28]}$ deposited $0.5-2 \mathrm{~nm}$ thick cobalt, iron and platinum at a $5-10^{\circ}$ angle with respect to the substrate normal; this was followed by an annealing process resulting in particles down to $2 \mathrm{~nm}$ in diameter which were subsequently used as catalytic seeds for chemical vapor deposition synthesis of single-walled carbon nanotubes. In contrast, employing chemical synthesis methods and cluster sources, particles smaller than $5 \mathrm{~nm}$ (down to subnanometer regime) on a support have been obtained with well-established processes, although these either have a broad size distribution or are poorly ordered. For example, in the studies involving gold and silver particles, Vajda and coworkers.[10d,29] compared the activity of subnanometer clusters and nanoparticles of about $2 \mathrm{~nm}$ in size using grazing incidence small angle X-ray scattering (GISAXS), a powerful tool to study the evolution of size and shape of supported clusters and nanoparticles under the reaction conditions. Chemical methods include strategies such as micelle and inverse micelle encapsulation, ${ }^{[30]}$ seed-mediated growth, ${ }^{[31]}$ polyol process, ${ }^{[32]}$ co-precipitation and deposition-precipitation, ${ }^{[33]}$ ionexchange, incipient wetness impregnation, and coimpregnation. ${ }^{[34]}$

\subsection{Nanofabrication Techniques for Large-area Patterning}

Since most characterization techniques require patterning over an area large enough to achieve good signal detection, it remains important to develop approaches to increase the throughput of top-down methods. In addition, EBL is generally limited with regards to the type of substrate that can be used for precise patterning, since the accumulation of charges on insulating substrates requires working with thin-films of these materials or the use of a conductive polymer in the process. These issues can be overcome using classic photolithography techniques, which are most relevant for high-throughput fabrication over large areas and on a variety of substrates. On the other hand, these approaches have limitations in the achievable feature sizes and pitch, and therefore only a few studies in catalysis have employed photolithography. One such example was demonstrated by Schildenberger et al., ${ }^{[35]}$ who performed laser interference lithography on a silica substrate to generate nano-sized holes (in the form of pits) down to $200 \mathrm{~nm}$ in diameter (with a pitch of the same size) inside which metals such as palladium, silver or copper were either deposited by evaporation (followed by lift-off) or directly spin-coated from a metal salt solution. The authors demonstrated coverage over a large area (a full 4-inch wafer), which constitutes the main advantage of this technique. They characterized the stability and chemical behavior of the resulting systems with XPS, AFM and SEM, proving their activity towards hydrogen and carbon monoxide oxidation. This type of sample was later used by Fokas and Deckert[36] to study single catalytic sites of thin palladium $(0.2 \mathrm{~nm})$ deposited on $50 \mathrm{~nm}$ thick silver islands in each pit, using Raman microscopy, although an in situ analysis was not possible. The diameter of the pits, and therefore of the particles, remained in the range of 200-300 nm, which was very large to guarantee any certainty in the nanoparticles' composition and homogeneity.

A number of other techniques have been employed to circumvent these limitations: (a) Colloidal or nanosphere lithography[37] - is an inexpensive method that combines top-down and bottom-up approaches, but which often results in particles without long-range order (more details in section $3.1)$; (b) Nanoimprint lithography ${ }^{[24 b, 38]}-$ is a low-cost, non-radiation-based lithography technique which allows the replication of a pattern over a large area. It uses a mold, also called template, that shapes the resist material into features and it does not have a diffraction limit in resolution. In recent years, sub-10 nm features have been achieved and it has the potential to go down further.[39] The main limitation is the ability to make the mold which is most often fabricated using conventional photolithography or EBL; (c) Size reduction lithography techniques - are a combination of different methods that promote the use of spacers and sacrificial materials to create nanowires, which have been used for catalysis. [38a,40] However, this technique does not allow nanoparticle arrays to be obtained due to it being limited to 2D structures; and (d) EUV lithography[3a,c] can potentially overcome all limitations regarding feature size, resolution and throughput mentioned in all previous techniques. It allows particles to be made with sub-10 $\mathrm{nm}$ resolution. Recently, we have shown that this technique, in the form of EUV-achromatic Talbot lithography (ATL) can yield uniform nanoparticle arrays of $15 \mathrm{~nm}$ diameter and $100 \mathrm{~nm}$ pitch over large areas (a square centimeter) with high throughput (vide infra, Fig. 4).

\subsection{Catalytic Results on Other Well-defined Systems}

Most nanofabricated model systems mentioned in previous sections have been employed to study the activity and stability of these metal particles in test reactions, such as carbon monoxide adsorption ${ }^{[17,21 b]}$ and ethylene hydrogenation, ${ }^{[24 a, c]}$ or to un- 
derstand active sites in more details.[21a] Other well-defined model systems have also been employed for catalysis, which can be improved significantly using nanolithography. Two such examples are 'bilayer tandem catalysts' and the 'inverse supported catalyst'. The nanocrystal bilayer employed by Somorjai and coworkers ${ }^{[41]}$ is a good example of engineering interfaces to perform tandem catalysis - sequential catalytic reactions on multiple metal-metal oxide interfaces. The bilayer consisted of two distinct metal-metal oxide interfaces, $\mathrm{CeO}_{2}-\mathrm{Pt}$ and $\mathrm{Pt}-\mathrm{SiO}_{2}$, obtained by assembling platinum and cerium oxide nanocube monolayers of less than $10 \mathrm{~nm}$ on a silica substrate and the authors used this catalyst for hydrocarbon conversion. The $\mathrm{CeO}_{2}-\mathrm{Pt}$ interface catalyzed methanol decomposition to produce carbon monoxide and hydrogen, which was subsequently used for ethylene hydroformylation catalyzed by the nearby $\mathrm{Pt}-\mathrm{SiO}_{2}$ interface. Consequently, propanal was produced selectively from methanol and ethylene on the nanocrystal bilayer tandem catalyst. Weiss and coworkers ${ }^{[42]}$ showed the concept of 'inverse supported catalysts' in which a well-defined $\mathrm{CeO} / \mathrm{Pt}(111)$ system was fabricated using the self-assembling of cerium adatoms on a $\mathrm{Pt}(111)$ surface with a subsequent oxidation of the nucleating cerium submonolayer ( $0.3 \mathrm{ML})$ to form $\mathrm{CeO}_{x}$ island between 5 and $15 \mathrm{~nm}$ in diameter and $0.3 \mathrm{~nm}$ in height. Carbon monoxide oxidation was performed while monitoring the carbon dioxide production rate and the ceria oxidation state. The authors observed higher reactivity of the $\mathrm{CeO}_{x} / \mathrm{Pt}(111)$ than of the clean $\operatorname{Pt}(111)$ surface. They later suggested an 'active border' concept to explain the strong local enhancement of catalytic activity[43] - the modified electron density is restricted to a few adsorption sites in the wide area around the $\mathrm{CeO}$ islands. Additional oxygen supply may originate via spillover from these regions. Such inverse catalysts were later employed in a number of studies, for example, by Rodriguez and colleagues. ${ }^{[44]}$ They performed carbon monoxide oxidation and WGS using inverse ceria/copper catalysts $(\mathrm{CeO} / \mathrm{Cu}(111))$ and showed that, even though bulk ceria has no activity towards these reactions, small amounts of ceria nanoparticles can activate the $\mathrm{Cu}(111)$ surface and achieve remarkable enhancement of its catalytic activity. The $\mathrm{CeO}_{x}$ nanoparticles facilitated the WGS reaction by acting at the interface with copper to dissociate water while these nanoparticles enhanced in the dissociation of oxygen for higher activity towards carbon monoxide oxidation. Nanolithography techniques can further improve the precision of 'inverse catalyst' systems or the 'bilayer tandem catalyst', which are both excellent model systems for systematic design and testing of the properties of novel catalytic systems.

\section{Applications of Top-Down Methods in Electrocatalysis}

In the framework of a sustainable hydrogen economy, polymer electrolyte fuel cells (PEFCs) and electrolysers are an important cornerstone to power the mobility sector and for peak shaving in the energy grid. ${ }^{45]}$ With platinum-based catalysts estimated to contribute between $20-45 \%$ to the overall PEFC-system cost, ${ }^{[46]}$ a large effort has been undertaken to reduce catalyst loading and to increase activity and durability. ${ }^{[47]}$ To provide a rational basis to these efforts, model systems have been employed throughout the last century, from single-crystal mono- and bimetallic surfaces, to thin films and metal nanoparticles on (high-surface area) carbon supports. ${ }^{[48]}$ Preparing the latter via conventional chemical synthesis, through size selection from a cluster source, or using magnetron sputtering, several groups have reported that catalyst activity depends on particle size ${ }^{[49]}$ and density. ${ }^{[50]}$ Whereas these preparation methods enable a narrow particle size distribution and controlled density, inter-particle distances are generally obtained only as a distribution of values. ${ }^{[32 b, 51]}$ While top-down lithography techniques are more suitable to address this model catalyst parameter, a wide-spread use thereof is hindered by the need for application-relevant particle sizes below $20 \mathrm{~nm}$, along with the high nanoparticle density and/or large patterned area required for a sufficient current response. Additionally, the high sensitivity of platinum to contamination and the fragility of the samples when submitted to the most common electrochemical cleaning methods, such as potential cycling, annealing and chemical cleaning, place high demands on the fabrication processes to obtain reproducible results. ${ }^{[52]}$ Using several fabrication steps puts tight demands on the design of the sample holders if the rotating disk electrode technique commonly applied for electrochemical kinetics studies, whereby the sample consists of a bulk cylinder, is to be used. ${ }^{[53]}$ Otherwise, alternative electrochemical cells allowing to assess square-shaped samples have to be designed ${ }^{[54]}$ and their current distribution profiles need to be computed to extract kinetically-relevant information from the measured diffusion-limited currents. Most efforts until today have therefore been placed on the fabrication of well-defined platinum nanoparticles with sizes below $50 \mathrm{~nm}$ and comparatively large interparticle distances as opposed to studies directed at the latter parameter.

\subsection{Colloidal Lithography for High Density Nanoparticles}

Colloidal lithography is especially suitable for patterning large areas in the square centimeter range with a high density of nanoparticles. First employed by Kasemo and coworkers to fabricate platinum on ceria and alumina surfaces, ${ }^{[37 b]}$ the method has also been applied to obtain $120 \mathrm{~nm}$ diameter platinum nanodisks on glassy carbon. ${ }^{[55]}$ Seidel et al. subsequently assessed the stability of the samples under typical conditions of electrocatalysis (i.e. potential cycling within $0.05 \mathrm{~V}$ to $1.6 \mathrm{~V}$ vs. the reversible hydrogen electrode (RHE)) and reported an improved treatment of the glassy carbon disks as well as the sputter deposition of the platinum films to increase their electrochemical stability. ${ }^{[56]}$ Studying the oxygen reduction reaction on these model catalysts in a dual thin-layer double-disk electrode flow cell,,57] Schneider et al. observed significant evolution of hydrogen peroxide from the proposed 'serial' mechanism of the oxygen reduction reaction. ${ }^{[58]}$ They attributed this behavior to the low probability for re-adsorption of hydrogen peroxide, and subsequent reduction/disproportionation to water, on model electrodes with a low density of platinum nanodisks. The preparation of electrodes with low densities led to a discrepancy between the expected and experimentally determined platinum coverage, prompting the investigation of the samples with high-resolution SEM. ${ }^{[59]}$ The authors observed an adlayer of approx. $5 \mathrm{~nm}$ diameter platinum nanoparticles between the $100-140 \mathrm{~nm}$ platinum nanodisks that contributed significantly to the total electrochemically active surface area. With the nanoparticles likely resulting from the argon sputtering step transferring the colloidal mask pattern into the underlying platinum film, an improved nanofabrication process termed hole-mask colloidal lithography was developed based on deposition and lift-off. The resulting model catalysts have been used to study the oxidation of carbon monoxide and methanol. ${ }^{[60]}$ In addition to the removal of undesired nanoparticles, hole mask colloidal lithography also enabled the fabrication of nanodisks with diameters around $50 \mathrm{~nm}$, significantly smaller than the $140 \mathrm{~nm}$ obtained through colloidal lithography and used to study formaldehyde oxidation. ${ }^{61]}$ The ability to control nanodisk density was applied by the same group to study mass transport phenomena and product selectivity. ${ }^{[62]}$ For mechanistically simple reactions, such as the oxidation of hydrogen and carbon monoxide, the authors observed an increasing current density with decreasing nanodisk density, indicating the transition from planar to hemispherical diffusion. For more complex reactions with at least one intermediate, the particle density 
and electrolyte flow rate influence not only current density but also product distribution, as in a desorption-re-adsorption-desorption reaction scheme, whereby the readsorption step is less likely to happen on model catalysts with low density or when applying a high flow rate resulting in a thin diffusion layer thickness.

\subsection{EBL-prepared Models in Electrochemistry}

Guzenko et al. used an EBL strategy that focused the electron-beam to a diameter of approximately $10 \mathrm{~nm}$, effectively patterning a single dot with a single beam shot ('single shot' technique) to achieve improved control over dot size and reasonable exposure time for dot arrays with 100 and $200 \mathrm{~nm}$ pitch. ${ }^{[63]}$ After a hardware modification to increase fine focus and astigmatism correction, 25-35 nm platinum nanoparticles were obtained over a large area on glassy carbon by the lift-off process. They also reported $13 \mathrm{~nm}$ gold nanoparticles obtained on silica with a chromium adhesion layer and the size of these particles could be reduced further to $6 \mathrm{~nm}$ by annealing at $600{ }^{\circ} \mathrm{C}$. Savouchkina et al. then used the same technique to fabricate $30 \mathrm{~nm}$ platinum nanoparticles on highly oriented pyrolytic graphite with a pitch of $200 \mathrm{~nm} .{ }^{[64]}$ Applying in situ scanning tunnelling microscopy, the authors reported the stepwise dissolution of platinum, whereby the particle height decreased from $2.5 \mathrm{~nm}$ to $0.5 \mathrm{~nm}$ at a potential of $1 \mathrm{~V}$ vs. the standard hydrogen electrode in $0.5 \mathrm{M} \mathrm{H}_{2} \mathrm{SO}_{4}$ and dissolved completely at potentials above $1.3 \mathrm{~V}$. The hole pattern left behind was later revealed to originate from the high energy platinum clusters deposited via magnetron sputtering as opposed to electron-beam evaporation, where no hole pattern was observed. ${ }^{[65]}$ Iddir et al. compared platinum nanoparticles fabricated by EBL and argon ion milling to a fabrication process combining both steps in one by focused ion beam lithography. ${ }^{[66]}$ After annealing in nitrogen at $1150^{\circ} \mathrm{C}, 100 \mathrm{~nm}$ platinum nanoparticles with $200 \mathrm{~nm}$ pitch were grown epitaxially on the low-index surfaces of niobium doped $\mathrm{SrTiO}_{3}$. In a subsequent study, the authors used the same nanofabrication process to obtain $30-40 \mathrm{~nm}$ diameter platinum nanoparticles with $200 \mathrm{~nm}$ pitch that were used as model electrocatalysts for the oxygen reduction reaction ${ }^{[67]}$ and displayed a reactivity proportional to the ratio of (100):(111) surface areas. With the close proximity of both facets in these model catalysts, Komanicky et al. suggested that the oxygen adsorbs on the (100) surfaces and diffuses to the (111) facets where it is reduced, thus explaining the activity increasing with the ratio of both facets $^{[27]}$ and confirming earlier studies on low-index platinum surfaces. ${ }^{68]}$ Using synchrotron X-ray scattering, the authors confirmed the crystal structure of the epitaxially-grown platinum nanoparticles and probed defects in the particle array.

\section{Our Recent Advances in Fabrication and Characterization of Model Systems}

\subsection{EBL Combined with Spectro- microscopy at the Single-particle Level}

Studies using EBL to obtain catalytic nanoparticle arrays have mostly targeted a large pitch above $100 \mathrm{~nm}$, since the liftoff process that follows the patterning of nano-wells and subsequent evaporation of the metal becomes challenging for smaller inter-particle distances. With the aim to reduce the pitch to below $100 \mathrm{~nm}$ and to achieve small particle sizes keeping exposure time to a minimum, we improved upon the 'single shot' technique for EBL exposure. ${ }^{[63]}$ We set the beam step size to $70 \mathrm{~nm}$ (equal to the required pitch) and fine-focused the beam to obtain high control over the particle size over a large area. After exposure and development of the positive-tone resist material resulting in optimal nano-wells, the deposition of the metal, such as iron, gold, chromium, niobium or platinum, could be done followed by the lift-off process. This resulted in uniform nanoparticle arrays down to $18 \mathrm{~nm}$ in diameter and with a pitch of $70 \mathrm{~nm}$ (SEM images in Fig. 1a and Fig. 1b). Both dimensions, in addition to the relatively short exposure time (less than one hour for a $2 \times$ $2 \mathrm{~mm}^{2}$ area) are substantial improvements compared to earlier studies on nanoparticle arrays. The particle size could be reduced further down to $12 \mathrm{~nm}$ using a cold developer after the exposure; the strategy of inclined evaporation before lift-off has the potential to yield even smaller particles.

The sequential nature of EBL can be employed to prepare model systems that do not need high-throughput or a large area. While there is no other chemical synthesis or lithography technique that can be used to obtain ordered nanoparticles of multiple sizes on the same support, this is clearly possible with EBL. As an alternative to using large nanoparticle arrays, we applied spectromicroscopy to probe nanoparticles at the single-particle level down to $6 \mathrm{~nm}$ in diameter using X-ray photoemission electron microscopy (X-PEEM) at the Swiss Light Source (Fig. 2a). Fig. 2b shows SEM of the model system consisting of well-defined iron oxide nanoparticles of nine different sizes from $80 \mathrm{~nm}$ in diameter down to $6 \mathrm{~nm}$ in a small $4 \times 4 \mu^{2}$ field-of-view that was obtained on the same silica support (with $2.5 \mathrm{~nm}$ particle height). ${ }^{[\mathrm{b}]}$ Such model systems use EBL exposure times of only a few minutes and each particle can be designed to have a highly precise geometry by implementing proximity effect correction strategies. X-PEEM enabled in situ visualization of chemical action on these particles with its capability of imaging the model system while spectroscopic measurements were performed. The XAS spectra from all particles could be extracted simultaneously under the same conditions and at the single nanoparticle level. Fig. 2c and $2 \mathrm{~d}$ show this for a $10 \mathrm{~nm}$ and $8 \mathrm{~nm}$ particle respectively. Reduction and oxidation of the system were carried out to elucidate size-effects during oxidation as the particle size reached the $6 \mathrm{~nm}$ dimension. Although a significantly higher rate of oxidation was seen for smaller sized particles, the atoms on the surface of any of these particles are equally reactive. ${ }^{[2 b]}$

\subsection{Controlling Distance between Particles with one Nanometer Precision and Elucidating the Spatial Extent of Hydrogen Spillover}

Through the advancement of combining nanofabrication and spectromicroscopy techniques we next investigated the mechanism of hydrogen spillover, a widely debated phenomenon in heterogeneous catalysis, explained in Fig. 3a. Hydrogen can dissociate over a metal catalyst, such as

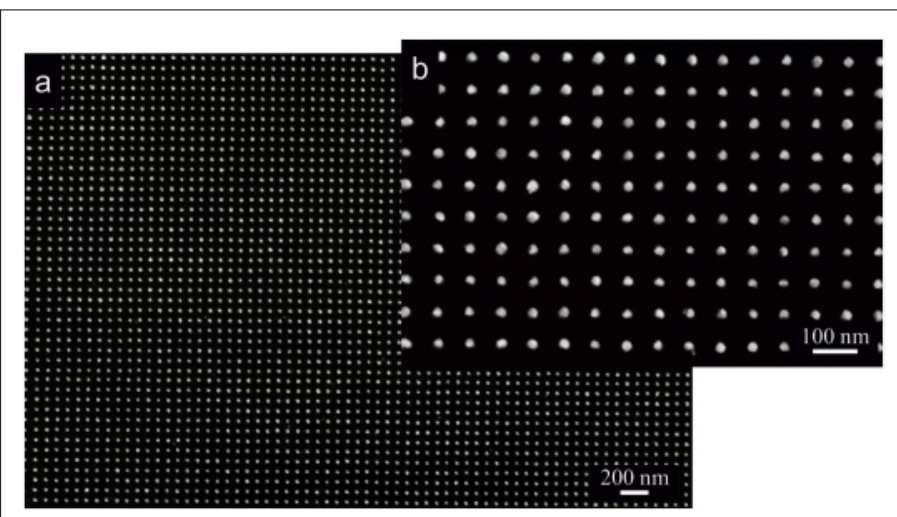

Fig. 1. Nanoparticle arrays obtained using EBL. (a) and (b) are low and high magnification SEM images, respectively, of iron nanoparticle arrays of $18 \mathrm{~nm}$ in diameter $(10 \mathrm{~nm}$ in height) with a pitch of $70 \mathrm{~nm}$ patterned over an area of $2 \times 2 \mathrm{~mm}^{2}$. 


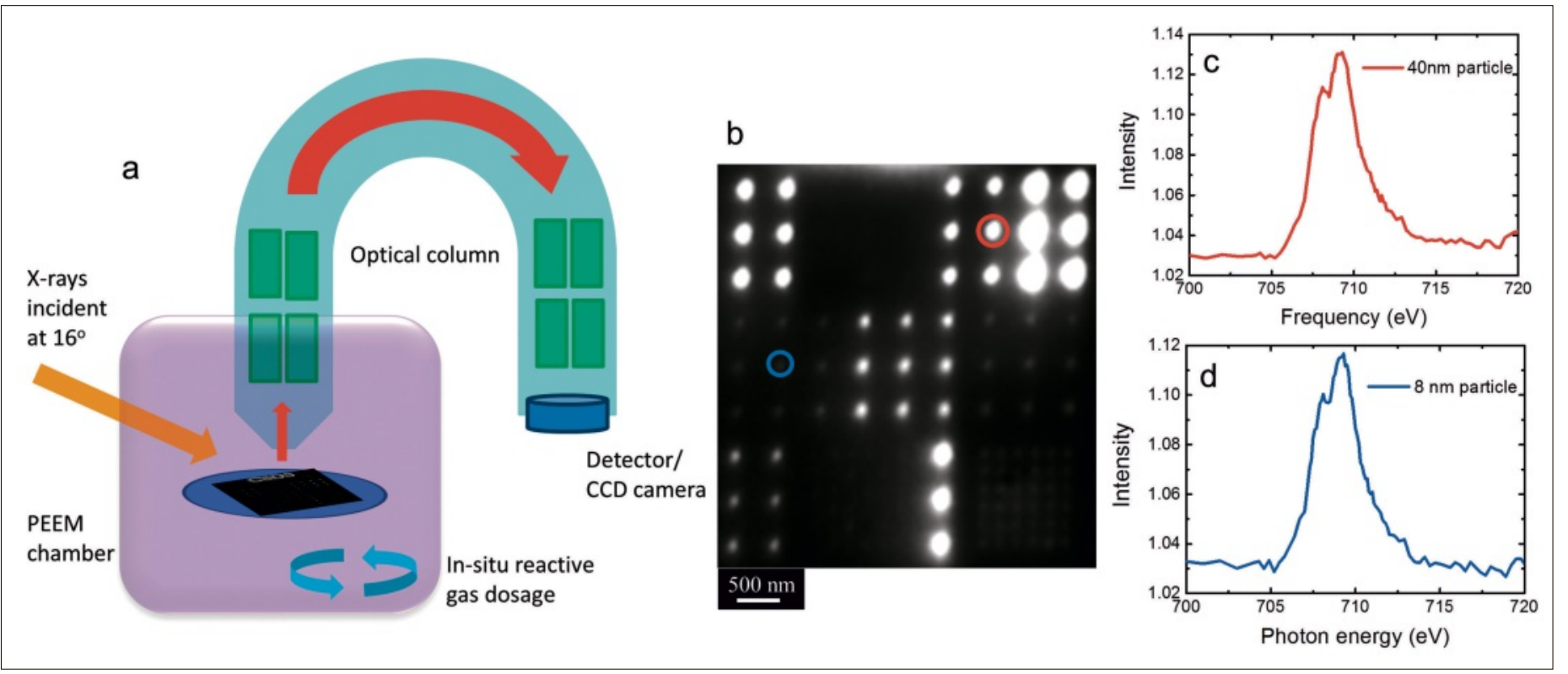

Fig. 2. (a) Schematic of the X-PEEM setup. Linearly polarized X-rays at the synchrotron are incident on the sample at an oblique angle. Secondary electrons emitted in response to the absorption of X-rays by the sample are recorded with a detector at the end of the optical column which converts the electron image to an elemental contrast image (photon image) (b) Elemental contrast image of a sample with EBL-prepared iron nanoparticles of nine different sizes (from 6 to $80 \mathrm{~nm}$ in diameter) in a $4 \times 4 \mu \mathrm{m}^{2}$ field-of-view. Two particles encircled in red (diameter $40 \mathrm{~nm}$ ) and blue (diameter $8 \mathrm{~nm}$ ) are selected for single-particle spectroscopy and the corresponding XAS spectra is shown in (c) and (d) respectively. Images reproduced from ref. [2b].

platinum in Fig. 3a, and promote a hydrogenation reaction on a different location, such as iron oxide reduction in Fig. 3c. This required transport of hydrogen over the catalyst support. It was generally accepted that hydrogen spillover occurs on a reducible support such as titania, but whether it occurs on a nonreducible support like alumina had been heavily disputed. We quantified the spatial extent of the spillover effect on alumina and titania support using an EBL-prepared model system. ${ }^{\text {[2a] }}$ While earlier EBL studies focused on obtaining a large number of well-ordered nanoparticles that are all the same, the potential to study inter-particle interactions among two kinds of nanoparticles has not been fully exploited. We developed a new method, which results in pairs of two different nanoparticles close to each other, whereby the distance is controlled with an unprecedented precision of one nanometer. On a thin film of these supports, in a $4 \times 4 \mu \mathrm{m}^{2}$ field-of-view, we placed one lone iron oxide particle and 15 pairs of iron oxide and platinum nanoparticles of $60 \mathrm{~nm}$ and $30 \mathrm{~nm}$ in diameter respectively, at different distances from each other ranging from 0 to $45 \mathrm{~nm}$ (Fig. 3b shows a similar system). The high precision of particle placement was achieved by overlay exposure involving three-step EBL and we compensated for the standard drift that would otherwise yield errors of $\pm 30 \mathrm{~nm}$ by scanning for all the errors greater than one nanometer, and therefore overcoming the inherent resolution limit of EBL.[69] To elucidate the phenomenon of hydrogen spillover, each of the 16 iron oxide particles were individually and simultaneously monitored by XAS in the X-PEEM before and after exposure to hydrogen to determine the degree to which each iron oxide nanoparticle was converted to metallic iron as a result of exposure to hydrogen. Fig. 3c shows the extent of reduction of iron oxide particles as a function of distance from platinum on the alumina support after hydrogen dosage at $343 \mathrm{~K}$. No reduction to metallic iron occurred in iron oxide particles that were further than $15 \mathrm{~nm}$ away from platinum, and their XAS spectra coincided with the XAS from the iron oxide particle without platinum. This implies that hydrogen cannot reach further than this distance by spillover. Evidence of spillover was observed for an inter-particle distance below $15 \mathrm{~nm}$, with increasing amount of reduction as the particles come closer to each other. On the other hand, equal reduction of all iron oxide particles was seen irrespective of their distance to platinum on a titania support. We also probed the surface of the support with spatial resolution of the X-PEEM around the individual pairs, and DFT calculations were employed to explain the observed spatial extent of hydrogen spillover on the two supports. We concluded that the restricted spillover on alumina is mediated by three-coordinated aluminum centers which also interact with water giving rise to a hydrogen desorption rate which is faster or comparable to the surface mobility. This causes a gradient in hydrogen coverage at the surface away from the platinum particle. Hydrogen that spilled over from platinum onto the alumina can therefore move only over a very short distance (below $15 \mathrm{~nm}$ ). On the other hand, spillover on reducible titania occurs via coupled proton-electron transfer with neither any competition with desorption nor with water coverage and is therefore highly efficient and uniform over large distances, thereby reducing remote iron oxide particles.[2a]

\subsection{Pairs of Nanoparticles in an Array over a Large Area}

Studies at the single-particle level are much less resource- and time-intensive when compared to the use of EBL for creating large arrays of nanoparticles, but need novel surface analysis tools. Similar to the phenomenon of hydrogen spillover, many other catalytic processes depending on inter-particle interactions cannot be characterized with commonly used tools unless pairs of particles are achieved over a large area. We created such model systems (Fig. 3d and Fig. 3e) using EBL to pattern nano-well arrays and subsequently employed inclined metal deposition on a rotatory stage to deposit two nanoparticles of different materials opposite to each other inside each of these nano-wells. In the past, a similar strategy was used for plasmonic applications by combining colloidal lithography with inclined deposition. ${ }^{[70]}$ We instead used EBL to create such ordered arrays of pairs, all of which had the same particle sizes and spacing between two types of particles. Tuning particle size and its separation was possible by decreas- 

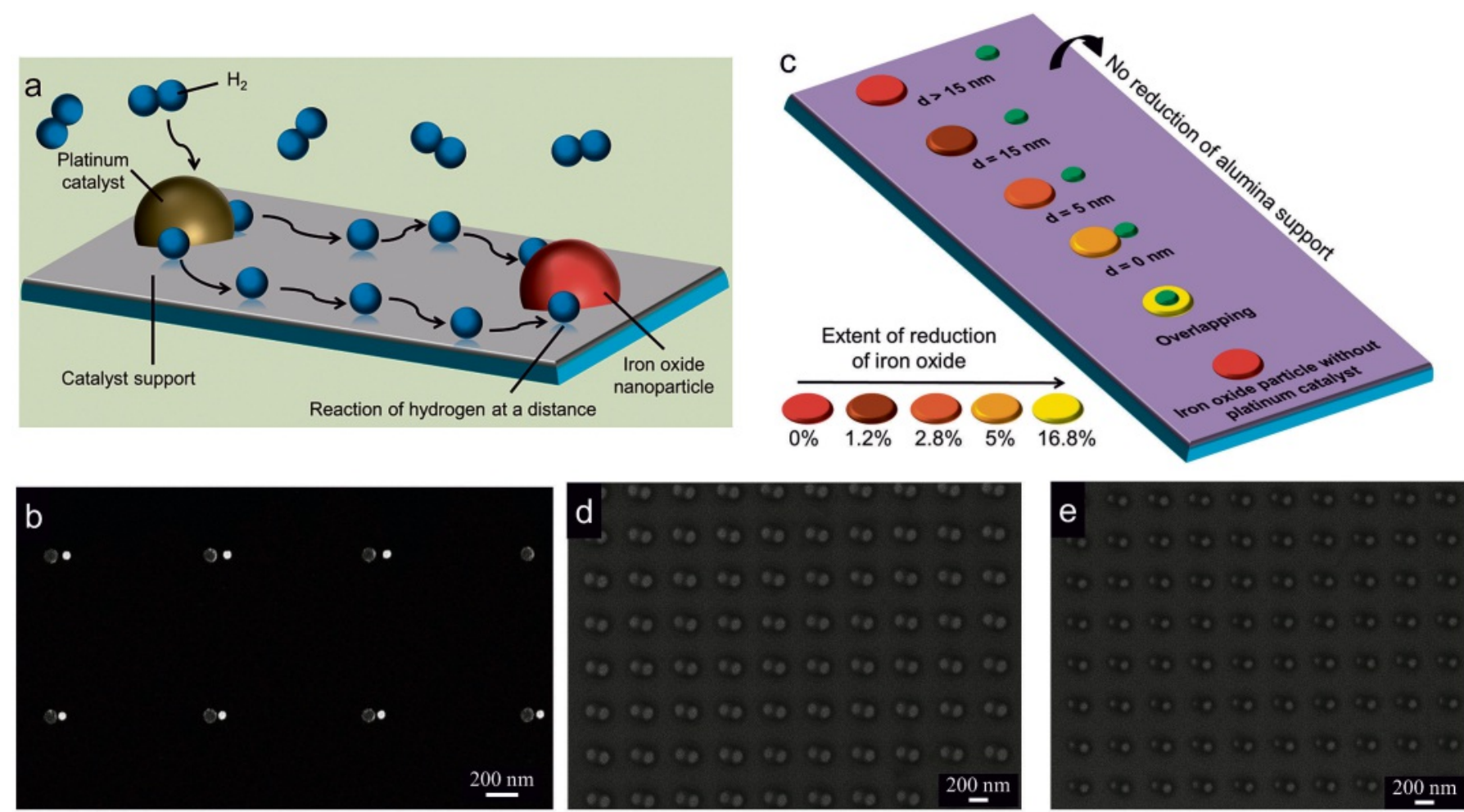

Fig. 3. (a) Schematic representation of hydrogen spillover which is the surface migration of activated hydrogen atoms from a metal catalyst particle (platinum here), on which they are generated, onto and along the catalyst support. These hydrogen atoms can then react with a remote species (iron oxide here) away from the catalyst. (b) SEM image of a model system similar to the one used to study hydrogen spillover in ref. [2a], consisting of a lone iron oxide particle (top-right corner) along with seven pairs of iron oxide and platinum particles (80 nm diameter and $2 \mathrm{~nm}$ thick, vs. $60 \mathrm{~nm}$ diameter and $15 \mathrm{~nm}$ thick, respectively), each with a different interparticle distance. (c) Illustration demonstrating the distance-dependent hydrogen spillover on the aluminium oxide support (Reproduced from ref. [2a]). (d) and (e) show SEM images of a model system consisting of arrays of the same pairs of iron and chromium nanoparticles; in (e), Iron and chromium diameters are $80 \mathrm{~nm}$ and $110 \mathrm{~nm}$, respectively, and the spacing is $60 \mathrm{~nm}$. In (f), the diameters are $40 \mathrm{~nm}$ and $85 \mathrm{~nm}$, and the spacing is $75 \mathrm{~nm}$.

ing the size of the nano-wells from $250 \mathrm{~nm}$ (Fig. 3d) to $200 \mathrm{~nm}$ (Fig. 3e) and by varying the deposition angle. This strategy can be combined with fabrication techniques that enable large-area patterning with high throughput, such as optical or EUV lithography, to obtain pairs of particles over an area of many square centimeters.

\subsection{Scope of Next-generation EUV Lithography for Large Area Patterning}

EUV interference lithography (EUVIL) uses the wavelength of light at $13.5 \mathrm{~nm}$ to pattern high-resolution periodic nanostructures, and the setup at the XIL-II beamline of the Swiss Light Source currently holds the world-record in resolution achieved with photolithography. ${ }^{[3 c, 71]}$ EUVATL, explained in Fig. 4a, enables patterning an area as large as $500 \times 500 \mu \mathrm{m}^{2}$ in a single-shot (corresponding to a few seconds) and seamless step-and-repeat exposures, allowing extension of patterns over an area of a few square centimeters in a few minutes. ${ }^{[3 a]}$ Using EUV-ATL, we have shown that nanoparticle arrays of $15 \mathrm{~nm}$ diameter and $100 \mathrm{~nm}$ pitch can be obtained on silica supports (Fig. 4b). ${ }^{[3 a]}$
With simple variations in the exposure dose, pairs of particles of two different sizes are also possible (Fig. 4c). As in the case of common optical lithography, the resist pattern needs to be transferred into a suitable metal, either via an etching process using a hardmask or through a lift-off process employing nano-wells. SEM images in Fig. 4d and Fig. 4e show platinum and iron nanoparticles obtained using the respective strategies. The size and pitch of the resulting particles are mainly limited by the transmission mask and further improvements in this will allow patterning metal nanoparticles at the resolution limit currently achieved by EUV lithography.

\subsection{Perspectives}

With novel nanofabrication techniques providing opportunities to create model systems that have particles with diameter below $5 \mathrm{~nm}$ and that are ordered, heterogeneously catalyzed reactions that become active only in this size-regime can be investigated. One such example is supported gold nanoparticles - a widely studied catalyst showing remarkable activity in the nanoscale, which is otherwise inert in bulk. ${ }^{25,72]}$ Gold shows different reactivity with small fluctuations in size between 2-5 $\mathrm{nm}$ for many reactions such as carbon monoxide oxidation, acetylene hydrochlorination, and $\mathrm{C}-\mathrm{H}$ activation reactions. In addition, the nanoparticles of similar size prepared with alternative methods or on different supports behave differently. Nanofabrication of gold particles with controlled structure, shape and size on nonreducible and reducible supports will serve as an ideal model system for these reactions as well as for simple studies on adsorption of carbon monoxide and oxygen, which may provide new insights into the processes underlying catalytic activity of gold in reduced dimensions and into the reaction mechanisms. The complexity of the behavior of gold increases when used in combination with other metals. ${ }^{[73]}$ For instance, bimetallic gold-palladium and trimetallic gold-palladium-platinum catalysts are highly active for methane oxidation and alcohol oxidation, respectively. Our development to obtain pairs of nanoparticles, that can also be extended to three particle systems or encapsulated systems, will not only allow detailed understanding of these types of catalysts by tuning the exact size and composition of the multiple metals, 


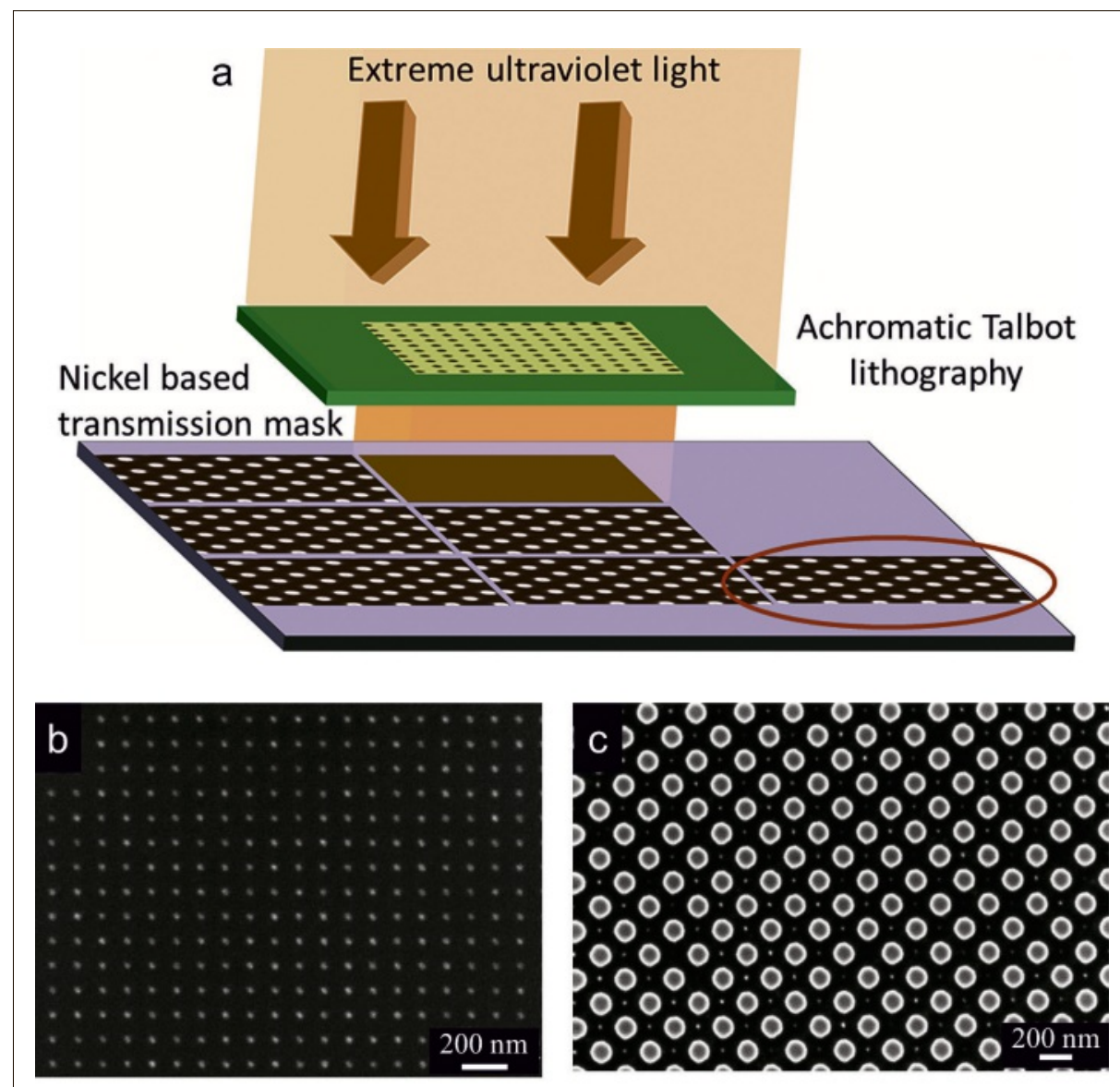

d
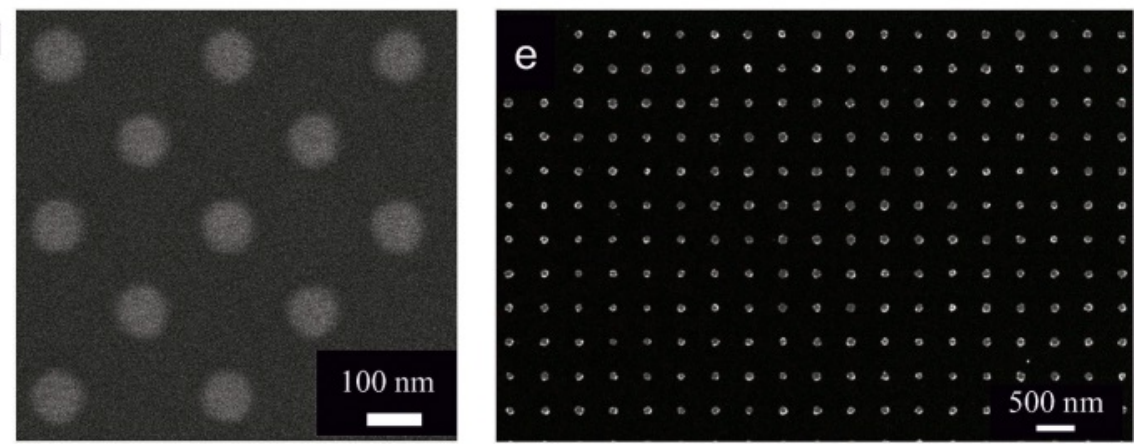

Fig. 4. Use of EUV-ATL to prepare catalytic nanoparticle arrays over a large area: Figs a-c are adapted and reproduced from ref. [3a] by permission of the Royal Society of Chemistry, a) Schematic of step-and-repeat ATL which requires a robust and reusable transmission mask through which EUV light passes and exposes the substrate covered with resist. b) SEM image after the exposure shows $15 \mathrm{~nm}$ particles of the resist with a pitch of $100 \mathrm{~nm}$ spread over a centimetre square area. c) SEM image after exposure at high dose resulting in pairs of particles of uniform sizes of $150 \mathrm{~nm}$ and $15 \mathrm{~nm}$. Pattern transfer to a metal requires development of etching or lift-off techniques. d) SEM image of platinum nanoparticles after pattern transfer via reactive ion etching. e) SEM image of iron nanoparticle arrays after lift-off process.

but will provide better understanding of the role of distance between the particles on different supports elucidating the synergy between the metals in these reactions. The role of interfaces in such catalysts and in multistep reactions can also be precisely studied using model systems in the form of a 'bilayer tandem catalyst', ${ }^{[41]}$ which is a powerful approach towards designing multifunctional catalysts and can be created by nanolithography as nanoparticle/nano- to quantify the proposed reverse spillover effect in photocatalysis ${ }^{[75]}$ providing new ways to approach the conversion of solar energy into chemical fuels such as hydrogen. In addition, our results on hydrogen spillover can be extended to a more detailed understanding of the support and the catalytic particle. For example, our theoretical calculations show that a certain geometry of platinum is more active and that the spillover process is favorable on alumina (100) interfaces. With the design of well-defined and faceted catalyst particles on single crystals, this can be experimentally shown using single-particle spectromicroscopy Additionally, atomic understanding of nanofabricated model systems is also required using computational methods to replicate large particles. This would help to predict the requirements of the model systems and to reduce the resources involved in characterization of such systems. As an alternative approach to metal on metal oxide, the 'active border' concept or 'inverse supported catalysts' [43] where a well-defined oxide particle covers a metal catalyst film may be used to overcome the stability issues of metal catalysts on support, permitting facile use of well-defined crystal facets of the metal and enhancing our understanding of processes at the metal-oxide interface during a reaction.

With state-of-the-art nanofabrication enabling well-defined bimetallic nanoparticle systems, model catalysts are also suited to study reactions in electrocatalysis proceeding over multiple intermediates or via dual-path mechanisms. One example is the oxidation of formic acid and the reverse reduction of carbon dioxide to formate on palladium-platinum surfaces. While the carbon monoxide intermediate poisons platinum surfaces, ${ }^{[76]}$ the oxidation on palladium preferably happens via dehydrogenation involving adsorbed $\mathrm{HCOO}$ species. ${ }^{[77]}$ Nanofabrication enables well-defined bimetallic systems of palladium-platinum, such as differently sized palladium nanoparticles on platinum thin films or on inactive support materials, palladiumplatinum core-shell or alloy structures via alloying, or arrays of the two metals with different interparticle distances. Studying not just the oxidation of formic acid but also the commercially relevant carbon dioxide reduction and concurrent hydrogen absorption into the palladium lattice, nanofabrication could help to shed light on unsolved questions in electrocatalysis.

The major driving force behind the development of nanofabrication methods has been the high-volume manufacturing of semiconductor devices. In accordance with the Moore's law, ${ }^{[78]}$ these developments have led to ever-shrinking devices and will continue to do so. The state-ofthe-art in nanofabrication has entered into 
the scale range that is also relevant for catalytic systems but the most interesting feature sizes between subnanometer to $5 \mathrm{~nm}$ are still extremely challenging. We believe that nanofabrication will become an increasingly powerful and important tool for understanding of fundamental questions in catalysis and to further improve industryrelevant catalytic processes.

\section{Conclusions}

Metal nanoparticle arrays are the most commonly used nanofabricated systems in catalysis. These metal nanoparticles need to be small in size, packed with high density and spread over a large area. A variety of techniques, such as EBL, photolithography, colloidal lithography, size reduction lithography, and EUV-ATL, have recently been employed to achieve the desired nanoparticle arrays. EBL is the most widely used method, yielding nanoparticles of diameters down to $6 \mathrm{~nm}$ and pitch down to $70 \mathrm{~nm}$ with the direct lift-off process, while particles of $2 \mathrm{~nm}$ diameter have also been reported by combining the fabrication technique with an inclined evaporation strategy. In addition, complex model systems consisting of pairs of two different nanoparticles can now be achieved with an unprecedented precision of one nanometer, which allows placement of particles close to each other to study the role of inter-particle distance in catalysis, such as to quantify the spatial extent of hydrogen spillover. These systems can also be extended over large areas using oblique evaporation strategies on a rotatory stage. EUV lithography is a next-generation technique that has great potential in catalysis, as it overcomes the low-throughput limitations of EBL and still allows very high resolution and feature sizes. At present, $15 \mathrm{~nm}$ sized particles can be obtained with a pitch of $100 \mathrm{~nm}$, while developments in mask fabrication strategies and etching processes will continue to provide a reduction of these dimensions. Various studies on nanoparticle arrays as model catalysts have been performed using XPS, XRD, and TEM, while recent developments have shown that studies are possible at the single-particle level without the need of having large area patterning. This has allowed a detailed understanding of particle size effects and of the roles of supports in stabilizing reaction intermediates. In addition to the developments in nanofabrication, novel surface science techniques in heterogeneous catalysis, further development in microreactors, and modified electrochemical cells in electrocatalysis are required, which will together open new opportunities to address the unresolved questions in both fields of catalysis.

\section{Acknowledgements}

Part of this work has been performed at the Swiss Light Source (SLS) of Paul Scherrer Institute (PSI). Vitaliy Guzenko and Michaela Vockenhuber are gratefully acknowledged for technical support with EBL and EUV lithography, respectively. We thank the PSI research commission for financial support within a CROSS initiative.

February 3, 2017

[1] M. J. Madou, 'Manufacturing techniques for microfabrication and nanotechnology', Vol. 2, CRC Press, 2011.

[2] a) W. Karim, C. Spreafico, A. Kleibert, J. Gobrecht, J. VandeVondele, Y. Ekinci, J. A. van Bokhoven, Nature 2017, 541, 68; b) W. Karim, A. Kleibert, U. Hartfelder, A. Balan, J. Gobrecht, J. A. van Bokhoven, Y. Ekinci, Sci. Rep. 2016, 6, 18818.

[3] a) W. Karim, S. A. Tschupp, M. Oezaslan, T. J. Schmidt, J. Gobrecht, J. A. van Bokhoven, Y. Ekinci, Nanoscale 2015, 7, 7386; b) D. Fan, E. Buitrago, S. Yang, W. Karim, Y. Wu, R. Tai, Y. Ekinci, Microelectro. Engin. 2016, 155, 55; c) E. Buitrago, R. Fallica, D. Fan, W. Karim, M. Vockenhuber, J. A. van Bokhoven, Y. Ekinci, Proc. SPIE 9926, 'UV and Higher Energy Photonics: From Materials to Applcations' 2016, 99260T.

[4] C. A. Busacca, D. R. Fandrick, J. J. Song, C. H. Senanayake, Ad. Synth. Catal. 2011, 353, 1825.

[5] C. Adams, Top. Catal. 2009, 52, 924.

[6] J. Kašpar, P. Fornasiero, N. Hickey, Catal. Today 2003, 77, 419.

[7] J. C. Serrano-Ruiz, J. A. Dumesic, Ener. Environ. Sci. 2011, 4, 83.

[8] a) M. S. Dresselhaus, I. L. Thomas, Nature 2001, 414, 332; b) P. V. Kamat, J. Phys. Chem. C 2007, 111, 2834.

[9] B. R. Cuenya, Thin Solid Films 2010, 518, 3127.

[10] a) A. T. Bell, Science 2003, 299, 1688; b) C. T. Campbell, S. C. Parker, D. E. Starr, Science 2002, 298, 811; c) M. Shekhar, J. Wang, W.-S. Lee, W. D. Williams, S. M. Kim, E. A. Stach, J. T. Miller, W. N. Delgass, F. H. Ribeiro, J. Am. Chem. Soc. 2012, 134, 4700; d) Y. Lei, F. Mehmood, S. Lee, J. Greeley, B. Lee, S. Seifert, R. E. Winans, J. W. Elam, R. J. Meyer, P. C. Redfern, D. Teschner, R. Schlögl, M. J. Pellin, L. A. Curtiss, S. Vajda, Science 2010, 328, 224; e) E. Roduner, Chem. Soc. Rev. 2006, 35, 583.

[11] a) D. W. Goodman, J. Catal. 2003, 216, 213; b) G. A. Somorjai, Surf. Sci. 1979, 89, 496; c) G. Ertl, H. J. Freund, Phys. Today 1999, 52, 32; d) H.-J. Freund, G. Pacchioni, Chem. Soc. Rev. 2008, 37, 2224; e) G. Ertl, Angew. Chem. Int. Ed. 2008, 47, 3524 .

[12] S. Khoobiar, J. Phys. Chem. 1964, 68, 411

[13] R. Prins, Chem. Rev. 2012, 112, 2714.

[14] G. A. Somorjai, Y. Li, Proc. Nat. Acad. Sci. USA 2011, 108, 917.

[15] P. W. Jacobs, F. H. Ribeiro, G. A. Somorjai, S. J. Wind, Catal. Lett. 1996, 37, 131.

[16] A. Avoyan, G. Rupprechter, A. S. Eppler, G. A. Somorjai, Top. Catal. 2000, 10, 107.

[17] S. Baldelli, A. S. Eppler, E. Anderson, Y.-R Shen, G. A. Somorjai, J. Chem. Phys. 2000, $113,5432$.

[18] G. A. Somorjai, R. M. Rioux, Catal. Today 2005, 100, 201

[19] a) K. Wong, S. Johansson, B. Kasemo, Faraday Dis. 1996, 105, 237; b) S. Johansson, E. Fridell, B. Kasemo, J. Vacuum Sci. Technol. A 2000, 18, 1514.
[20] A. W. Grant, Q.-H. Hu, B. Kasemo, Nanotechnol. 2004, 15, 1175 .

[21] a) J. Shan, A. Chakradhar, M. Komarneni, U. Burghaus, J. Phys. Chem. C 2012, 116, 18930; b) M. Komarneni, J. Shan, A. Chakradhar, E. Kadossov, S. Cabrini, U. Burghaus, J Phys. Chem. C 2012, 116, 5792.

[22] J. Shan, A. Chakradhar, K. Anderson, J. Schmidt, S. Dhuey, U. Burghaus, in 'Nanotechnology for Sustainable Energy', Vol. 1140, American Chemical Society, 2013, p. 295.

[23] a) A. S. Eppler, G. Rupprechter, E. A. Anderson, G. A. Somorjai, J. Phys. Chem. B 2000, 104 , 7286; b) S. Johansson, E. Fridell, B. Kasemo, J. Catal. 2001, 200, 370; c) T. Tsirlin, J. Zhu, J. Grunes, G. A. Somorjai, Top. Catal. 2002, 19, 165.

[24] a) J. Grunes, J. Zhu, E. A. Anderson, G. A Somorjai, J. Phys. Chem. B 2002, 106, 11463; b) A. M. Contreras, J. Grunes, X.-M. Yan, A. Liddle, G. A. Somorjai, Catal. Lett. 2005, 100, 115 ; c) A. M. Contreras, J. Grunes, X. M. Yan, A. Liddle, G. A. Somorjai, Top. Catal. 2006, 39, 123.

[25] M.-C. Daniel, D. Astruc, Chem. Rev. 2004, 104, 293.

[26] Y. Sun, L. Zhuang, J. Lu, X. Hong, P. Liu, J. Am. Chem. Soc. 2007, 129, 15465.

[27] V. Komanicky, H. Iddir, K.-C. Chang, A. Menzel, G. Karapetrov, D. Hennessy, P. Zapol, H. You, J. Am. Chem. Soc. 2009, 131, 5732.

[28] A. Javey, H. Dai, J. Am. Chem. Soc. 2005, 127, 11942.

[29] S. Lee, L. M. Molina, M. J. López, J. A. Alonso, B. Hammer, B. Lee, S. Seifert, R. E. Winans, J. W. Elam, M. J. Pellin, S. Vajda, Angew. Chem. Int. Ed. 2009, 48, 1467.

[30] a) J. R. Croy, S. Mostafa, J. Liu, Y.-h. Sohn, B. Roldan Cuenya, Catal. Lett. 2007, 118, 1; b) R. Reske, H. Mistry, F. Behafarid, B. Roldan Cuenya, P. Strasser, J. Am. Chem. Soc. 2014, 136, 6978; c) B. Roldan Cuenya, J. R. Croy, S. Mostafa, F. Behafarid, L. Li, Z. Zhang, J. C. Yang, Q. Wang, A. I. Frenkel, J. Am. Chem. Soc. 2010, 132, 8747

[31] P. Prieto, V. Nistor, K. Nouneh, M. Oyama, M. Abd-Lefdil, R. Díaz, Appl. Surf. Sci. 2012, 258, 8807.

[32] a) T. Herricks, J. Chen, Y. Xia, Nano Lett. 2004, 4, 2367; b) F. Fiévet, R. Brayner, in 'Nanomaterials: A Danger or a Promise? A Chemical and Biological Perspective', Eds. R. Brayner, F. Fiévet, T. Coradin, Springer London, London, 2013, p. 1.

[33] M. Haruta, M. Daté, Appl. Catal. A 2001, 222, 427.

[34] a) R. Zanella, S. Giorgio, C. R. Henry, C. Louis, J. Phys. Chem. B 2002, 106, 7634; b) D. J. Ostgard, L. Kustov, K. R. Poeppelmeier, W. M. H. Sachtler, J. Catal. 1992, 133, 342.

[35] a) M. Schildenberger, Y. Bonetti, M. Aeschlimann, L. Scandella, J. Gobrecht, R. Prins, Catal. Lett. 1998, 56, 1; b) M. Schildenberger, Y. Bonetti, R. Prins, in 'Studies in Surface Science and Catalysis', Vol. 130, Eds. F. V. M. S. M. Avelino Corma, G. F. José Luis, Elsevier, 2000, p. 1121; c) M. Schildenberger, Y. C. Bonetti, J. Gobrecht, R. Prins, Top. Catal. 2000, 13, 109.

[36] C. Fokas, V. Deckert, Appl. Spectro. 2002, 56, 192.

[37] a) L. Österlund, A. W. Grant, B. Kasemo, in 'Nanocatalysis', Springer, 2007, p. 269; b) C. Werdinius, L. Österlund, B. Kasemo, Langmuir 2003, 19, 458

[38] a) X. M. Yan, S. Kwon, A. M. Contreras, J. Bokor, G. A. Somorjai, Nano Lett. 2005, 5, 745; b) C. Zhang, X. Huang, H. Liu, S. J. Chua, C. A. Ross, Nanotechnol. 2016, 27, 485604.

[39] S. Y. Chou, P. R. Krauss, W. Zhang, L. Guo, L. Zhuang, J. Vacuum Sci. Technol. B 1997, 15, 2897. 
[40] Y.-K. Choi, J. S. Lee, J. Zhu, G. A. Somorjai, L. P. Lee, J. Bokor, J. Vacuum Sci. Technol. B 2003, 21, 2951.

[41] Y. Yamada, C.-K. Tsung, W. Huang, Z. Huo, S. E. Habas, T. Soejima, C. E. Aliaga, G. A. Somorjai, P. Yang, Nat. Chem. 2011, 3, 372.

[42] Y. Suchorski, R. Wrobel, S. Becker, B. Strzelczyk, W. Drachsel, H. Weiss, Surf. Sci. 2007, 601, 4843 .

[43] Y. Suchorski, R. Wrobel, S. Becker, H. Weiss, J. Phys. Chem. C 2008, 112, 20012.

[44] S. D. Senanayake, D. Stacchiola, J. A Rodriguez, Acc. Chem. Res. 2013, 46, 1702.

[45] a) J. O. M. Bockris, Int. J. Hydrogen Ener. 2013, 38, 2579; b) G. A. Olah, A. Goeppert, G. S. Prakash, 'Beyond oil and gas: the methanol economy', John Wiley \& Sons, 2011.

[46] a) S. Satyapal, M. Mills, S. Byham, Z. Hou, K. Nahm, International Partnership for Hydrogen and Fuel Cells in the Economy (IPHE), Washington, DC 2008; b) J. Marcinkoski, J. Spendelow, A. Wilson, D. Papageorgopoulos, US Department of Energy, 2015.

[47] A. Rabis, P. Rodriguez, T. J. Schmidt, ACS Catal. 2012, 2, 864.

[48] a) N. M. Marković, P. N. Ross Jr, Surf. Sci. Rep. 2002, 45, 117; b) K. A. Friedrich, K. P. Geyzers, A. J. Dickinson, U. Stimming, J. Electroanal Chem. 2002, 524, 261; c) R. J. Behm, Z. Jusys, J. Power Sources 2006, 154, 327.

[49] a) K. J. J. Mayrhofer, B. B. Blizanac, M. Arenz, V. R. Stamenkovic, P. N. Ross, N. M. Markovic, J. Phys. Chem. B 2005, 109 14433; b) F. J. Perez-Alonso, D. N. McCarthy, A. Nierhoff, P. Hernandez-Fernandez, C. Strebel, I. E. L. Stephens, J. H. Nielsen, I. Chorkendorff, Angew. Chem. Int. Ed. 2012, 51, 4641; c) K. J. J. Mayrhofer, M. Arenz, B B. Blizanac, V. Stamenkovic, P. N. Ross, N M. Markovic, Electrochim. Acta 2005, 50, 5144; d) M. Nesselberger, S. Ashton, J. C. Meier, I. Katsounaros, K. J. J. Mayrhofer, M. Arenz, J. Am. Chem. Soc. 2011, 133, 17428 e) P. Hernandez-Fernandez, F. Masini, D. N McCarthy, C. E. Strebel, D. Friebel, D. Deiana, P. Malacrida, A. Nierhoff, A. Bodin, A. M Wise, J. H. Nielsen, T. W. Hansen, A. Nilsson, E. L. StephensIfan, I. Chorkendorff, Nat. Chem. 2014, 6, 732; f) M. Arenz, K. J. J. Mayrhofer V. Stamenkovic, B. B. Blizanac, T. Tomoyuki, P. N. Ross, N. M. Markovic, J. Am. Chem. Soc. 2005, 127, 6819 .

[50] a) M. Nesselberger, M. Roefzaad, R. Fayçal Hamou, P. Ulrich Biedermann, F. F. Schweinberger, S. Kunz, K. Schloegl, G. K. H. Wiberg, S. Ashton, U. Heiz, K. J. J. Mayrhofer, M. Arenz, Nat. Mater. 2013, 12, 919; b) J. Speder, L. Altmann, M. Baumer, J. J. K
Kirkensgaard, K. Mortensen, M. Arenz, RSC Adv. 2014, 4, 14971; c) E. Fabbri, S. Taylor, A. Rabis, P. Levecque, O. Conrad, R. Kötz, T. J. Schmidt, Chem CatChem 2014, 6, 1410.

[51] a) S. Cheong, J. Watt, B. Ingham, M. F. Toney, R. D. Tilley, J. Am. Chem. Soc. 2009, 131, 14590; b) A. Chen, P. Holt-Hindle, Chem. Rev. 2010, 110, 3767; c) A. Stepanov, A. Golubev, S. Nikitin, Y. Osin, Rev. Adv. Mater. Sci. 2014, 38, 160.

[52] K. Shinozaki, J. W. Zack, R. M. Richards, B. S. Pivovar, S. S. Kocha, J. Electrochem. Soc. 2015, 162, F1144.

[53] T. Schmidt, H. Gasteiger, G. Stäb, P. Urban, D. Kolb, R. Behm, J. Electrochem. Soc. 1998, 145, 2354.

[54] S. E. Temmel, S. A. Tschupp, T. J. Schmidt, Rev. Sci. Instr. 2016, 87, 045115.

[55] M. Gustavsson, H. Fredriksson, B. Kasemo, Z. Jusys, J. Kaiser, C. Jun, R. J. Behm, J. Electroanal. Chem. 2004, 568, 371.

[56] Y. E. Seidel, R. W. Lindström, Z. Jusys, M. Gustavsson, P. Hanarp, B. Kasemo, A. Minkow, H. J. Fecht, R. J. Behm, J. Electrochem. Soc. 2008, 155, K50.

[57] Z. Jusys, J. Kaiser, R. J. Behm, Electrochim. Acta 2004, 49, 1297.

[58] A. Schneider, L. Colmenares, Y. E. Seidel, Z. Jusys, B. Wickman, B. Kasemo, R. J. Behm, PhysChemChemPhys 2008, 10, 1931.

[59] Y. E. Seidel, M. Müller, Z. Jusys, B. Wickman, P. Hanarp, B. Kasemo, U. Hörmann, U. Kaiser, R. J. Behm, J. Electrochem. Soc. 2008, 155, K171.

[60] a) H. Schwechten, M. Heinen, Y. E. Seidel, Z. Jusys, B. Wickman, B. Kasemo, R. J. Behm, J. Electroanal. Chem. 2011, 662, 157; b) Y. E. Seidel, A. Schneider, Z. Jusys, B. Wickman, B. Kasemo, R. J. Behm, Langmuir 2010, 26, 3569.

[61] Y. E. Seidel, Z. Jusys, R. W. Lindström, M. Stenfeldt, B. Kasemo, K. Krischer, ChemPhysChem 2010, 11, 1405.

[62] a) Y. E. Seidel, A. Schneider, Z. Jusys, B Wickman, B. Kasemo, R. J. Behm, Faraday Dis. 2009, 140, 167; b) Y. E. Seidel, Z. Jusys, B. Wickman, B. Kasemo, R. J. Behm, ECS Trans. 2010, 25, 91; c) R. W. Lindström, Y. E. Seidel, Z. Jusys, M. Gustavsson, B. Wickman, B. Kasemo, R. J. Behm, J. Electroanal. Chem. 2010, 644, 90.

[63] V. A. Guzenko, J. Ziegler, A. Savouchkina, C. Padeste, C. David, Microelectr. Engin. 2011, 88, 1972.

[64] A. Savouchkina, A. Foelske-Schmitz, V. A. Guzenko, D. Weingarth, G. G. Scherer, A. Wokaun, R. Kötz, Electrochem. Commun. 2011 13,484 .
[65] A. P. Savouchkina, PhD thesis, ETH Zürich, 2012.

[66] H. Iddir, V. Komanicky, S. Ögüt, H. You, P. Zapol, J. Phys. Chem. C 2007, 111, 14782

[67] V. Komanicky, H. Iddir, K.-C. Chang, A Menzel, G. Karapetrov, D. C. Hennessy, P. Zapol, H. You, Electrochim. Acta 2010, 55, 7934.

[68] a) V. Komanicky, W. R. Fawcett, J. Electroanal. Chem. 2003, 556, 109; b) V. Komanicky, A. Menzel, K.-C. Chang, H. You, J. Phys. Chem B 2005, 109, 23543; c) N. M. Marković, R. R. Adžić, B. D. Cahan, E. B. Yeager, J. Electroanal. Chem. 1994, 377, 249; d) N. Markovic, T. Schmidt, V. Stamenkovic, P. Ross, Fuel Cells 2001, 1, 105.

[69] a) V. R. Manfrinato, J. Wen, L. Zhang, Y. Yang, R. G. Hobbs, B. Baker, D. Su, D. Zakharov, N. J. Zaluzec, D. J. Miller, E. A. Stach, K. K. Berggren, Nano Lett. 2014, 14, 4406; b) V. R. Manfrinato, L. Zhang, D. Su, H. Duan, R. G. Hobbs, E. A. Stach, K. K. Berggren, Nano Lett. 2013, 13, 1555,

[70] A. Kiristopuryan, Y. Ekinci, R. Giannini, P. K. Sahoo, G. Gorodyska, J. F. Löffler, Appl. Phys. Lett. 2009, 95, 231903.

[71] N. Mojarad, M. Hojeij, L. Wang, J. Gobrecht, Y. Ekinci, Nanoscale 2015, 7, 4031.

[72] a) C. Lemire, R. Meyer, S. Shaikhutdinov, H.-J. Freund, Angew. Chem. Int. Ed. 2004, 43, 118; b) A. Sanchez, S. Abbet, U. Heiz, W. D. Schneider, H. Häkkinen, R. N. Barnett, U. Landman, J. Phys. Chem. A 1999, 103, 9573.

[73] S. J. Freakley, Q. He, C. J. Kiely, G. J Hutchings, Catal. Lett. 2015, 145, 71

[74] Y. Zhai, D. Pierre, R. Si, W. Deng, P. Ferrin, A U. Nilekar, G. Peng, J. A. Herron, D. C. Bell, H. Saltsburg, M. Mavrikakis, M. FlytzaniStephanopoulos, Science 2010, 329, 1633.

[75] J. B. Joo, R. Dillon, I. Lee, Y. Yin, C. J. Bardeen, F. Zaera, Proc. Nat. Acad. Sci. USA 2014, 111, 7942.

[76] J. L. Haan, K. M. Stafford, R. D. Morgan, R. I. Masel, Electrochim. Acta 2010, 55, 2477.

[77] A. Capon, R. Parsons, J. Electroanal. Chem. Interfacial Electrochem. 1973, 44, 239.

[78] a) G. E. Moore, Proc. IEEE 1998, 86, 82; b) R. R. Schaller, IEEE Spectrum 1997, 34, 52; c) C. A. Mack, IEEE Trans. Semiconductor Manufacturing 2011, 24, 202. 